\title{
Maintaining independence in the cognitively intact elderly care home population: a systematic review of intervention trials
}

\author{
Catherine J Evans, Claire Goodman and Sally Redfern \\ King's College London (KCL/UCL ), London, UK
}

\section{Background}

Over the last two decades, the care home sector has been a significant provider of long-term care for older people, with 11500 homes providing care for 236700 people across England and Wales. New admissions to residential care homes are increasingly older, aged 80 and over and have high levels of physical dependency, cognitive impairment and behavioural problems. ${ }^{2,3}$

With increases in life expectancy, care of the older person has become a prominent issue for public health policy. A major goal of UK health and social policy in old age is the maintenance of independence. ${ }^{4,5}$ Although there is a body of literature that documents the health needs of older people in care homes and the effectiveness of public health nursing for community-dwelling elderly people, ${ }^{6}$ no work has considered how existing primary health care services can work to improve older residents' health status. This mini-review aims to contribute to this limited research area by answering the question: What interventions by nurses are effective in maintaining independence in the cognitively intact elderly care home population?

\section{Method}

The review is underpinned by the principles of the 'mini-review. ${ }^{7}$ This follows a similar format of a full systematic review. ${ }^{8}$ Unlike a full review however, a mini-review tends to address a single focussed question and typically a single, as opposed to multiple, outcomes. Maintaining independence is the outcome measure of interest here. The review aimed to produce a systematic and

\footnotetext{
Address for correspondence: C Evans, Research Fellow, Primary Care Nursing Research Unit, King's College London, James Clerk Maxwell Building, 57 Waterloo Road, London. SE1 8WA, UK.
}

unbiased search of the literature that was explicit and replicable, and critically appraised those studies that met the search inclusion criteria.

\section{Search strategy}

A facet analysis was conducted on the main search question, breaking it down into three components: population (two facets, (1) elderly and (2) care home); intervention (intention to maintain independence); and outcome (maintenance of independence). Each facet was analyzed to identify the keywords and index terms (Table 1) to be used in the database searches. Database searches were conducted on the Cochrane Library to ascertain if a review had already been completed on the area of interest, Medline (1966-2003), CINAHL (1982-2003) and Embase (1980-2003).

The keyword searching included only words or phrases identified in the facet analysis as describing the components of the question. The use of synonyms is considered as enhancing the sensitivity of the search. ${ }^{9}$ For the population component, two facets were needed, one describing people aged over 65 years and the other the care home setting. Table 1 details their respective keywords. The population was also described as being cognitively intact. This was defined as people either with no history of cognitive impairment, or at the mild end of the dementia sequelae. At this early stage, it was considered that the search strategy needed to be sensitive to all elderly care home residents, rather than specific to the cognitively intact.

The intervention was not known. A broad statement of its intention to maintain independence was stated in the question analysis, but no keywords were used. This broad statement as to the intention of the intervention, combined with a stated outcome of independence, was considered sufficiently explicit to generate a sensitive search 
Table 1: Question component facet analysis and search terms

\begin{tabular}{llll}
\hline \hline Population & & Intervention & Outcome \\
Elderly & Care home & Intervention & Independence \\
& & & \\
Independence & Nursing home & Interventions by nurses & Independence \\
Elderly & Residential facility & that intend to maintain & Activities of daily living \\
Old & independence & Barthel Index \\
Frail elderly & Intermediate care & Functional Independence \\
& Skilled care facility & & Measure (FIM) \\
& & Katz \\
\hline
\end{tabular}

\begin{tabular}{llll}
\hline \multicolumn{2}{c}{ Search terms (keyword and index terms) } & & \\
\hline Elder\$ & A Carc home\$ & A & Independence\$ \\
Or & N Or & N & Or \\
Aged & D Residential & D & Activities of Daily Living \\
Or & facilities/ or Nursing & & Or \\
Old & homes/Long-term & Barthel Index \\
Or & care & Or \\
'Aged, 80 and over' & Or & Functional Independence \\
or & Intermediate care & Instrument \\
Frail elder\$ & facilities & Or \\
Or & Or & Katz \\
Frail Elderly & Intermediate care & \\
& facilities & \\
& Or & \\
& Nursing home\$ & \\
& Or & \\
& Residential & \\
& facilities & \\
& Or & \\
& Skilled nursing care & \\
& facility\$ & \\
& Or & \\
& Skilled nursing & \\
& facility/ A & \\
\hline
\end{tabular}

\$ Sign used as a truncation for free text keywords when more than one ending was possible.

strategy. Independence was described by using the term itself and three measures of function. Criteria for the inclusion of a function measurement scale were that it be widely used in either or both the UK and US and had been validated as a measure of disability or function with older people. The Barthel Index, ${ }^{10}$ the Katz Index of Independence $^{11}$ and the Functional Independence Measure $^{12}$ met these criteria and were included in the search strategy.

In the database searches, the keywords were entered as free text and with a truncation (e.g. elders, where more than one ending was possible. For each keyword, their index term (or medical subject heading (MeSH)) was searched for. Those that were synonymous with the keyword were selected and exploded under all subject headings. For example, the population keyword 'care home' corresponded to the MeSH index headings 'residential facilities', 'nursing homes' and 'long-term care'. These were included within the search strategy. Results within each question component were combined using the Boolean operator 'or' to give a set of references that contained any or all of the terms. The Boolean operator 'and' was then used to combine each of the three components of the question to give references specific to the question. A RCT methodological filter was then applied to the saved subject search and combined, using the Boolean operator 'and', to give a specific set of references that reported on the effectiveness of interventions to maintain independence in the 


\begin{tabular}{|c|c|c|c|}
\hline$\#$ & Search History & Results & Annotations \\
\hline 1 & $\begin{array}{l}\text { Elder } \$ \text {.mp. [mp=title, abstract, cas registry/ec number word, mesh } \\
\text { subject heading] }\end{array}$ & 87349 & \multirow{6}{*}{$\begin{array}{l}\text { Truncated key } \\
\text { terms and mapped } \\
\text { index terms to } \\
\text { describe the } \\
\text { population aged } \\
\text { over } 65 \text { years. }\end{array}$} \\
\hline 2 & Aged/ & 1294706 & \\
\hline 3 & $\begin{array}{l}\text { Old } \$ . m p . \text { [mp=title, abstract, cas registry/ec number word, mesh } \\
\text { subject heading] }\end{array}$ & 431516 & \\
\hline 4 & $\exp$ 'Aged 80 and over' & 236394 & \\
\hline 5 & $\begin{array}{l}\text { frail elder } \$ . m p . \text { [mp=title, abstract, cas registry/ec number word, } \\
\text { mesh subject heading] }\end{array}$ & 3043 & \\
\hline 6 & exp frail elderly & 2566 & \\
\hline 7 & 1 or 2 or 3 or 4 or 5 or 6 & 1631172 & $\begin{array}{l}\text { Boolean term 'or' } \\
\text { combines terms }\end{array}$ \\
\hline 8 & $\begin{array}{l}\text { Care homes. mp. [mp=title, abstract, cas registry/ec number word, } \\
\text { mesh subject heading] }\end{array}$ & 1654 & \multirow{7}{*}{$\begin{array}{l}\text { Truncated key } \\
\text { words and } \\
\text { mapped index } \\
\text { terms describing } \\
\text { care homes }\end{array}$} \\
\hline 9 & $\begin{array}{l}\text { Exp residential facilities/ or exp nursing homes/ or exp long-term } \\
\text { Care/ }\end{array}$ & 40439 & \\
\hline 10 & $\begin{array}{l}\text { Intermediate care facilit } \$ . \mathrm{mp} \text {. [mp=title, abstract, cas registry/ec } \\
\text { number word, mesh subject heading] }\end{array}$ & 537 & \\
\hline 11 & exp Intermediate Care Facilities/ & 448 & \\
\hline 12 & $\begin{array}{l}\text { Nursing home.mp. [mp=title, abstract, cas registry/ec number } \\
\text { word, mesh subject heading] }\end{array}$ & 21914 & \\
\hline 13 & $\begin{array}{l}\text { Skilled nursing facility.mp. [mp=title, abstract, cas registry/ec } \\
\text { number word, mesh subject heading] }\end{array}$ & 3081 & \\
\hline 14 & Exp skilled nursing facilities & 2730 & \\
\hline 15 & 8 or 9 or 10 or 11 or 12 or 13 or 14 & 44758 & $\begin{array}{l}\text { Boolean term 'or' } \\
\text { combines terms }\end{array}$ \\
\hline
\end{tabular}




\begin{tabular}{|c|c|c|c|}
\hline$\#$ & Search History & Results & Annotations \\
\hline 16 & $\begin{array}{l}\text { Independen } \$ . m p \text {. [mp=title, abstract, cas registry/ec number word, } \\
\text { mesh subject heading] }\end{array}$ & 286827 & \multirow{2}{*}{$\begin{array}{l}\text { Truncated key } \\
\text { words and } \\
\text { mapped index } \\
\text { terms describing } \\
\text { the independence } \\
\text { outcome }\end{array}$} \\
\hline 17 & Exp Activities of Daily Living/ & 23731 & \\
\hline 18 & $\begin{array}{l}\text { Barthel index.mp. [mp=title, abstract, cas registry/ec number word, } \\
\text { mesh subject heading] }\end{array}$ & 920 & \\
\hline 19 & $\begin{array}{l}\text { Functional independence measure } \$ . m p \text {. [mp=title, abstract, cas } \\
\text { registry/ec number word, mesh subject heading] }\end{array}$ & 563 & \\
\hline 20 & $\begin{array}{l}\text { Katz\$.mp. [mp=title, abstract, cas registry/ec number word, mesh } \\
\text { Subject heading] }\end{array}$ & 1076 & \\
\hline 21 & 16 or 17 or 18 or 19 or 20 & 308328 & $\begin{array}{l}\text { Boolean term 'or' } \\
\text { combines terms }\end{array}$ \\
\hline 22 & 7 and 15 and 21 & 2863 & $\begin{array}{l}\text { Boolean term 'and' } \\
\text { combines }\end{array}$ \\
\hline 23 & Randomized controlled trial.pt. & 173860 & $\begin{array}{l}\text { Methodological } \\
\text { filter (sensitive) }\end{array}$ \\
\hline 24 & Dt.fs. & 932648 & \\
\hline 25 & Tu.fs. & 1006109 & \\
\hline 26 & Random.tw. & 258877 & \\
\hline 27 & or/23-26 & 1456782 & \\
\hline 28 & 22 and 27 & 329 & $\begin{array}{l}\text { Boolean term 'and' } \\
\text { combines search } \\
\text { and filter }\end{array}$ \\
\hline 29 & Limit 50 to (human and English language) & 298 & $\begin{array}{l}\text { Limited to English } \\
\text { and human } \\
\text { studies }\end{array}$ \\
\hline
\end{tabular}

\$ $\$$ sign used as a truncation for free text keywords when more than one ending was possible

Figure 1 Annotated copy of search strategy conducted on MEDLINE (1966 to May Week 2 2003). 
elderly care home population. Figure 1 details an annotated example of the Medline search.

The search strategy yielded a reasonable number of references for each of the three electronic databases used (Medline 298, CINHAL 110 and Embase 156). To ensure the validity of the studies included in the review, inclusion criteria were developed stating that:

- The study needed to be a randomized controlled trial or a systematic review of randomized trials.

- The population consisted of people aged over 65 years living in a residential facility who were cognitively intact. Cognitively intact people were defined as those able to follow two simple commands. This meant the inclusion of a population with mild dementia and depression, but the exclusion of those with severe dementia.

- The population resided in an institutional facility that provided either or both residential, nursing or rehabilitative care, but was not an acute hospital unit.

- The intervention described needed to have the intention to maintain independence as one of its main outcome measures and

- The intervention should be within the remit of the role of a nurse.

The data to be extracted from the studies was specific to the outcome of maintaining independence. The extent to which an intervention maintained independence was to be assessed by extracting data from the functional status measures used in the studies. Because the question was concerned about continuing and enhancing independence, data on patient acceptability, the sustainability of the intervention and its continued effect would also be extracted in the form of participation rates and follow-up data.

\section{Findings of the review}

\section{Study selection}

From a review of the titles and abstracts, sixteen studies were initially identified from the electronic databases as meeting the search inclusion criteria. When all the papers in the studies had been reviewed, six were considered to meet the inclusion criteria.Table 2 tabulates their main design features, study populations and findings. Two papers by Mulrow et al., ${ }^{13,14}$ however, reported the same study and were treated as a single study. Exercise programmes were the sole intervention in the five studies reviewed.

Ten papers were excluded (see Table 3), seven 15-21 because the majority of their population was cognitively impaired at the severe end of the dementia sequelae. A further two by Blair 22, 23 used a quasi-experimental design to test two nursing approaches and their effect on residents' ability to self-care. The study groups were formed from two selected units in a nursing home. Nonrandomization can result in selection bias because the study population does not have equal opportunity to be in either group. ${ }^{24} \mathrm{~A}$ third paper by O'Hagan et al. ${ }^{2.5}$ on exercise classes in rest homes was found from examining the reference lists of the studies reviewed. The maintenance of independence was not one of the main outcome measures in this study and a case-control design was used. The paper was hence rejected.

\section{Critique of the studies included}

The five studies in the review all used an RCT design to test the effectiveness of exercise with elderly care home residents; one of their main outcome measures was independence. Study results on independence will be the focus of the critical appraisal. Requisite components of an RCT are used to structure the critique, namely: randomization; sample size; blinding; and duration and completeness of follow-up. ${ }^{y}$ The findings of each study are then presented.

Random allocation of a sample population to the study groups is important to avoid systematic bias. ${ }^{9}$ Four of the studies ${ }^{14,26-28}$ randomized the sample population to the study groups at gold standard level, using sealed envelopes and random numbers. ${ }^{24} \mathrm{~A}$ fourth study by McMurdo et al. ${ }^{29}$ randomly sampled the local care home population ( $n=12$ ), selecting and randomly allocating four homes to the study groups, again at gold standard level. Selective sampling was used by the remaining four studies. This increases the risk of selection bias and needs to be considered when reviewing the studies' conclusions and their application to practice. Once randomized into their study groups, the five studies presented a statistical baseline analysis. This enabled consideration of the validity of each study. ${ }^{24}$

Sample size calculations were detailed in two studies. ${ }^{26,28}$ Sufficient sample size is required in 







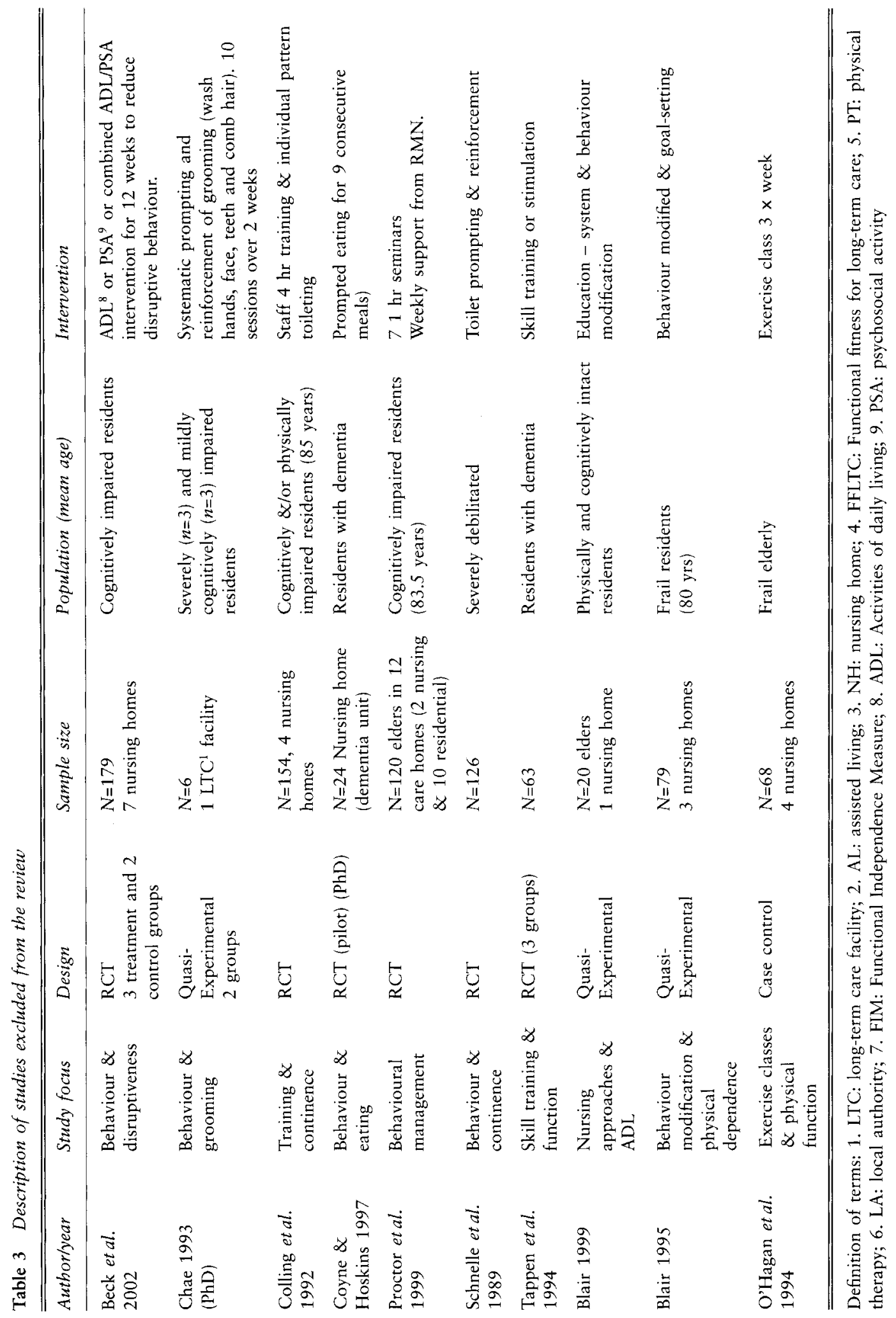


a study to ensure the sample is large enough to ascertain differences between the study groups.? Baum et al. ${ }^{26}$ calculated the sample size after sample recruitment, to justify that a semi-crossover design with a small sample of 20 residents could give $80 \%$ power at alpha $=0.05$, with 0.5 standard deviation effect size. Meuleman et al. ${ }^{28}$ calculated that 43 participants were needed in each study group (allowing for $30 \%$ dropout) to give $80 \%$ power at alpha $=0.05$ with a 2 point differential in the functional assessment scale. Fifty-eight participants comprised the final study population, but only $42 \%(n=24)$ of those completed the 12-month post-test. The study was therefore underpowered.

Mulrow et al. ${ }^{14}$ stated that a posterior power calculation demonstrated that the sample size of 194 was adequate to detect clinically significant results with $80 \%$ power at alpha $=0.05$. The calculation was not described but, given the large sample size and high participation rate $(93 \%)$, the study was viewed as sufficiently powered. Lazowiski et al. ${ }^{27}$ provided no sample size calculation. With a reasonable sample size $(n=96)$ and participation rate $(82.5 \%)$. the study was considered sufficiently powered. However, both these studies reported inconclusive differences in the independence outcome measures between the study groups. This raises questions about their power. McMurdo et al..$^{29}$ also provided no sample size calculations. Although with a smaller sample size $(n=49)$ but good participation rate $(83.6 \%)$, the study was considered sufficiently powered. Significant differences were reported between the two arms of the trial.

Follow-up rates of participants entering the studies were over $80 \%$ in the five studies reviewed. It is an indication of methodological quality that the majority of the participants were accounted for. Single- and double-blinding as a measure of quality was, however, harder to ascertain. Lazowski et al. ${ }^{27}$ and Baum et al. ${ }^{26}$ both stated blinded observers had been used for all outcome measures. Mulrow et al. ${ }^{14}$ and Meuleman et al. ${ }^{28}$ however, used blinded observers, but the activities of daily living (ADL) outcome measures (Katz and PADL/IADL, respectively) were either completed, or confirmed by the participants' primary care nurse, who was not blinded as to their study group. Baum et al. maintained observerblinding by using a simulated independence outcome measure (7-point Physical Performance Test
$(\mathrm{PPT}))^{30}$; Lazowski et al. ${ }^{27}$ used their own trained observers. These were also the only double-blind trials. Baum et al. ${ }^{26}$ blinded their participants by comparing two different exercise programmes, and Lazowski et al. ${ }^{27}$ used a crossover design. McMurdo et al..$^{29}$ was the only study with a nonblind observer. Observer bias is likely, causing possible systematic differences in outcome assessment. ${ }^{9}$ Conclusions drawn from the study needed to be treated cautiously.

Duration of follow-up went beyond completion of the intervention in three studies. ${ }^{14,26,28}$ Demonstration of the sustained effect of the intervention on maintaining independence was of particular interest in the review. It is unfortunate that this data is limited and is further hampered by the high loss of participants, in particular in the study of Meuleman et al., ${ }^{28}$ with $58 \%$ dropout at 12 months.

\section{Results}

In randomized controlled trials, any measure of outcome between the arms of the study is ideally accompanied by a $95 \%$ confidence interval (CI). This is when authors state the probability for $p$ value) that a particular outcome would have occurred by chance; the confidence interval of the highest and lowest point of the measurement spread is stated. ${ }^{9}$ The size of the confidence interval and whether it crosses zero gives an indication of the certainty of the findings and their positive or negative nature. ${ }^{9}$ The outcome of interest here is the effect of the intervention on maintaining independence as measured by a functional or disability scale. The results are presented in Table 2.

\section{Baum et al. (2003)}

Baum et al. ${ }^{26}$ recruited 21 residents from a single 50-bed long-term care (LTC) facility who met their eligibility criteria. This excluded those who were acutely unwell, unable to follow a two-step command, had assaultive behaviour patterns or were currently receiving physical therapy. Twenty residents participated in the study, five from the nursing home and 15 from the residential care unit. The intervention comprised one hour-long seated exercise sessions three times a week for six months, delivered by an exercise physiologist and trained LTC staff. Recreational sessions (e.g. painting) were given to the control group for the 
same duration. At the end of six months, the groups crossed over. This was non-random and there was no separating period without treatment. On completion of the crossover, participants were followed up for six months.

Three measurement scales were used to measure functional outcomes: the timed Get-up-andGo $(T U G)^{31}$; Berg Balance scale ${ }^{32}$; and Physical Performance Test (PPT). ${ }^{30}$ A functional independence scale (FIM) ${ }^{12}$ was used for group baseline analysis, but not as an outcome measure. The FIM needs to be administered by trained staff, in this case the nurses, who could not be blinded. The results are presented as overall effects. Raw measurements are presented at the six-month crossover, but not the nine- and 12-month posttests. In the overall effects data, positive differences between the study groups were reported for the TUG (CI: .12, .95) and the PPT (CI: .002, .80); a negative effect was seen for the Berg scale (CI: $-.09, .74)$. No $P$ values were stated. The spread of all three CIs were wide, casting doubt on the certainty of the findings. This may in part be because of the small sample size, and likely underpowering of the study. The authors acknowledge the small sample size as a limitation of the study, but assert that their findings are significant because the $P$ value for the global test (all function measures and cognition measure combined) was 0.013 . No CI is presented for this $P$ value. If the cognitive outcome measure is excluded, the $P$ value of the three functional measures alone is 0.068 . No CI is given. The study's conclusion that exercise causes a significant and positive effect on function in elderly care home residents is treated cautiously.

\section{Lazowski et al. (1999)}

Lazowski et al. ${ }^{27}$ approached 96 elderly residents from five LTC institutions that met their eligibility criteria. This excluded persons with medical contraindications to exercise, but not those with dementia. However, those cognitively unable to follow the exercises $(n=3)$ dropped out of the programme. Twenty-eight residents in total dropped out at baseline. They were all accounted for. Sixtyeight residents completed the study. These were randomized to receive either the Functional Fitness for Long-Term Care (FFLTC) Program or Range of Motion (ROM) exercises. The programmes were provided by LTC staff who had completed the Long-Term Care Physical Activity Workshop. Sessions lasted for 45 minutes, three times per week for the four-month evaluation period. Attendance rates for the FFLTC $(86 \%)$ and ROM $(79 \%)$ were high. Functional ability was assessed by specially trained and blinded personnel using the FIM. ${ }^{12}$ FIM scores can range from 18 to 126 ; higher scores indicate higher function.

Baseline FIM scores were high in both groups (FFLTC, 114.7, SD 8.9; ROM, 110.4 SD 15.4). FIM scores in the FFLTC $(n=34)$ were maintained (114.8, CI 111.9-117.7) and declined by $8 \%$ in the ROM ( $n=31$ ) group (105.2, CI 99.6-110.8). The difference between the two groups was significant at the $p=0.05$ level. The high functional level at the start of the programme, maintenance of this in the FFLTC condition and decline in the ROM would indicate a positive effect of the FFLTC intervention over ROM in maintaining independence. The small CI effect however, indicates the need for more research to demonstrate a clinically significant effect. A longer follow-up period to demonstrate sustained effect and continued patient acceptability is also indicated.

\section{McMurdo et al. (1993)}

McMurdo et al. ${ }^{29}$ is the only UK study reviewed. The authors recruited 49 elderly residents from four local authority care homes; each home was randomized to receive either twice weekly 45 minute exercise sessions, or reminiscence sessions of an equal duration. Residents with communication difficulties were excluded. Forty-one completed the seven-month project. All participants were accounted for. Attendance at both the exercise $(91 \%)$ and reminiscence groups $(86 \%)$ was high. The Barthel Activities of Daily Living (ADL) Index ${ }^{10}$ and chair-to-stand time(s) were the independence outcome measures. ADL characteristics were not included in the baseline data presented. The seven-month follow-up data reported a onepoint (2.8) increase in the exercise groups' ADL score, compared to a one-point (2.8) decline in that of the reminiscence groups $(p=0.05$, CI 0.1 to 3.8). Quite a wide CI spread casts uncertainty over the clinical significance of the results. Chairto-stand-time gave a more definitive outcome measure of difference between the study groups $(p=0.001, \mathrm{CI}-1.5$ to $-0.5, \mathrm{NB}:-\mathrm{ve}$ finding $=+$ ve result). 


\section{Meuleman et al. (2000)}

Meuleman et al. ${ }^{28}$ recruited elderly subjects from three care home sites: (1) a Veterans Affairs (VA) nursing home, (2) a rehabilitation unit and (3) a community nursing home. Fifty-eight of the 78 volunteers met the inclusion criteria. Participants were selected if they needed help with one or more Physical Activities of Daily Living (PADL), ${ }^{33}$ and had potential for improvement. The principal investigator, who knew the residents, ascertained subject eligibility based upon their PADL score, duration of disability and coexistent medical problems. The inclusion of subjective eligibility criteria may mean the non-randomization of all eligible patients. Participation in the trial may only be offered to people considered likely to respond well to the intervention. ${ }^{9}$

The training group $(n=26)$ received thriceweekly resistance training and twice weekly endurance training conducted in groups of two, with a physical therapist and aide for eight weeks. The control group $(n=32)$ received usual care. Two functional status measures were used (PADL and the Instrumental ADL, (IADL)). ${ }^{33}$ At the initial eight-week post-test, the training groups PADL, IADL and the two scales combined, improved by $0.9,0.6$ and 1.5 compared to the controls. These were not significant $(p=.13, .19$ and .10). No CIs were given. By stratifying the study groups into those with high dysfunction (score $<13 / 26$ ) (training, $n=17$; control, $n=16$ ) and low dysfunction (score>13/26) a $2.7 \mathrm{ADL}$ score difference was seen between the study groups with high dysfunction $(p=.042)$. No CI is given. The differences were stated as not sustained at the six- and 12-month post-test measures (no figures are given). The ADL item of 'Can you walk?' was reported in the initial post-test as showing the most improvement. Again, only the $p$ value of .021 is stated. The Spearman correlation coefficient test was used to ascertain a relationship between change in strength and change in combined ADL score $(n=58)$. An association was seen with the isometric $(.32, p=.016)$, concentric $(.21, p=.108)$ and eccentric $(.36, p=$ $0.006)$ measures. No CIs were given. Given the otherwise comprehensive nature of the study's findings, the unpublished raw ADL data could be requested from the authors if time and resources allowed.
Mulrow et al. (1994)

In this study, ${ }^{14} 194$ elderly residents were recruited from nine nursing homes. All were dependent in at least two ADL. Participants received either one to one physical therapy or friendly visits three times a week for three months. The Katz ADL ${ }^{11}$ was used as the measure of functional capacity. A negative main ADL outcome measure was seen ($0.4 \%, p=.80$, CI -4.6 to 3.7$)$. The only positive result was in a $15 \%$ improvement in the mobility subscale of the Physical Disability Index (PDI) ${ }^{34}$ $(p=0.1, \mathrm{CI}: 6.4$ to 24.7$)$. Although the wide CI means uncertainly about the findings, what is interesting is that no differences between the study groups were seen in the individual ADL that assessed mobility and transfers. The ADL data was taken from participants' records, completed by their nurse. This raises questions about the accuracy of ADL data collated by institution staff.

\section{Discussion}

The review sought to answer what interventions by nurses were effective in maintaining independence in the cognitively intact older care home population. The limitations of the studies to answering this question were grouped into three main categories :

1) The identification of a single intervention type of exercise programme

2) The validity of the functional scales and sample size, particularly in the follow-up data

3) Sample populations comprising cognitively intact older residents

The evidence to answer the question is limited to exercise. Methodological difficulties hampered the validity of the functional status measures used, most notably, the Barthel index. McMurdo et al. ${ }^{29}$ questioned its sensitivity to differing levels of mobility, and commentators, its reliability to detect change over time. ${ }^{35}$ Moreover, the need for trained personnel to administer functional status measures resulted in three studies using nonblinded observers. ${ }^{14,28,29}$

Only two studies ${ }^{26,28}$ incorporated post-test measures after completion of the intervention in their study design. The data of Meuleman et al..$^{28}$ was hampered by high dropout rates at six months $(n=24 / 58)$ and 12 months $(n=6 / 34)$. Data on only $42 \%(n=24)$ of the sample was available at 12 months. The authors did not present this 
post-test data. Baum et al. did not present their nine-month and 12-month post intervention data, preferring to use an overall effects data analysis. The evidence available to the review cannot comment on the sustainability of the intervention in the maintainance of independence. Both these issues highlight methodological challenges when conducting research in an area of limited knowledge and with a population who frequently have complex health and social care needs.

The main limitation of the review was the inclusion of only cognitively intact study populations. This may enable older people with severe dementia to be viewed as having special needs, ${ }^{27}$ but ignores the UK practice reality that $61 \%$ of the care home population have a degree of cognitive impairment. ${ }^{3}$ This limits the applicability of the findings to practice. Table 3 gives an overview of these studies. The overall limitation is, however, the lack of data synthesis. This was not possible because limited resources and time precluded synthesizing outcome data from the eight different function scales used in the studies. Instead, the pattern of the results was presented.

In answering the critics' question of 'What interventions are effective in maintaining independence in the care home population?' a positive direction of the effectiveness of exercise programmes in maintaining ADL was evident, except for Mulrow et al,,$^{13}$ who reported a negative effect. These findings however, may be related to a systematic bias with non-blinded LTC staff collecting the Katz ADL data. With the wide confidence intervals reported in the five studies and limited statistical significance, the overall results did not demonstrate a clinically significant effect, rather the need for more research in the area. Future studies could usefully develop the findings of a greater effect of exercise on elderly persons with high dysfunction ${ }^{28}$ compared to those with low dysfunction, ${ }^{27}$ and the benefit of strength training on the lower body, ${ }^{28}$ rather than reparation of movement. ${ }^{13,27}$

\section{Conclusions}

For practice, it is evident that the introduction of exercise in the care home setting could have positive benefits for the residents. The programme needs however, to be designed specifically for frail elders, to be able to be delivered in a care home setting and be provided by suitably trained indi- viduals $\mathrm{A}$ future area of primary research would be how to develop this type of intervention in the UK using existing primary care and care home staff to deliver the programme.

\section{Acknowledgements}

The Research Fellowship of the lead author is funded by the National Primary Care Researcher Development Awards, Department of Health, England. Guidance to undertake the systematic review was given by Professor Ian Norman and Dr. Peter Griffiths while participating in the Evidence-Based Health Care Course at King's College London.

\section{References}

1 Greenhalgh T, Donald A. Evidence-based bealth care workbook. London: BMJ Publishing Group, 2000.

2 Medical Research Council CFAS. Profile of disability in elderly people. BMJ 1999; 318: 1108-11.

3 Godlove Mozley C, Challlis D, Sutcliffe C. Psychiatric symptomatology in elderly people admitted to nursing and residential homes. Ageing Ment Health 2000; 4: 13-41.

4 Department of Health. National Service Framework for Older People. London: Department of Health, HMSO, 2000.

5 Department of Health. The New NHS-modern and dependable. London: The Department of Health, HMSO, 1997.

6 Elliot L, Crombie IK, Irvine L, Cantrell J, Taylor J. The effectiveness of public health nursing: a review of systematic reviews. Dundee: University of Dundee, 2002.

7 Griffiths P. Evidence informing practice: introducing the mini-review. Br J Comm Nurs 2002; 7: 38-40.

8 NHS Centre for Reviews and Dissemination. Undertaking systematic reviews of research on effectiveness. CRD report no.4. York: CRRE, 2001.

9 Greenhalgh T. How to read a paper: the basics of evidence-based medicine. London: BMJ Publishing Group, 1997.

10 Colin C, Wade DT, Davies S, Horne V. The Barthel ADL Index: a reliability study. Int J Disabil Stud 1988; 19: 61-63.

11 Katz S, Ford AB, Moskowitz RW et al. Studies of illness in the aged. The index of ADL: a standardized measure of biological psychosocial function. JAMA 1963; 185: 914-19. 
12 Granger CV and Hamilton BB. Performance profiles of the Functional Independence Measure. Am J Phys Med Rehabil 1993; 72: 84-89.

13 Mulrow CD, Gerety MB, Kantern D, DeNino LA, Cornell JE. The effects of physical therapy on functional status of nursing home residents. $J \mathrm{Am}$ Geriatr Soc 1993; 41: 326-29.

14 Mulrow CD, Gerety MB, Kantern D et al. A randomized trial of physical rehabilitation for very frail nursing home residents. JAMA 1994; 271: $519-24$

15 Beck CK, Vopgelpophl TS, Rasin JH et al. Effects of behavioural interventions on disruptive behaviour and affect in demented nursing home residents. Nurs Res 2002; 51: 219-28.

16 Chae YML. Development of a behavioural nursing intervention strategy in grooming performance of elders with cognitive impairment [Doctoral dissertation]. Arizona: University of Arizona, 1993.

17 Colling J, Ouslander J, Hadley BJ, Eisch J, Campbell $\mathrm{E}$. The effects of patterned urge-response toileting on urinary incontinence among nursing home residents. J Am Geriatr Soc 1992; 40: 135-41.

18 Coyne ML and Hoskins L. Improving eating behaviours in dementia using behavioural strategies. Clin Nurs Res 1997; 6: 275-90.

19 Proctor R, Burns A, Powell HS et al. Behavioural management in nursing and residential homes: $A$ randomised controlled trial. Lancet 1999; 354: 26-29.

20 Schnelle JF, Traughber B, Sowell VA et al. Prompted voiding treatment of urinary incontinence in nursing home patients. A behaviour management approach for nursing home staff. $J$ Am Geriatr Soc; 37: 1051-57.

21 Tappen RM. The effect of skill training on functional abilities of nursing home residents with dementia. Res Nurs Health 1994; 17: 159-65.

22 Blair CE. Combining behaviour management and mutual goal-setting to reduce physical dependency in nursing home residents. Nurs Res 1995; 44: $160-65$.

23 Blair CE. Effect of self-care ADLs on self-esteem of intact nursing home residents. Issues Ment Health Nurs 1999; 20: 559-70.

24 Sackett D Strauss S, Richardson W et al. Evidence- based medicine. How to practice and teach EBM, second edition. New York: Churchill Livingstone, 2000.

25 O'Hagan CM, Smith Dmand, Pileggi KL. Exercise classes in rest homes: effect on physical function. NZ Med J 1994; 107: 39-40.

26 Baum EE, Jarjovra D, Polen AE, Faur D, Rutecki G. Effectiveness of a group exercise program in a long-term care facility: a randomized pilot trial. JAMA 2003; 4: 74-80.

27 Lazowski DA, Ecclestone NA, Myers AM et al. A randomized outcome evaluation of group exercise programs in long-term care institutions. J Gerontol Nurs Series A-Biol Sci Med Sci 1999; 54: M621-M628.

28 Meuleman JR, Brechue WF, Kubilis PS, Lowenthal DT. Exercise training in the debilitated aged: strength and functional outcomes. Arch Phys Med Rebabil 2000; 81: 312-18.

29 McMurdo ME and Rennie L. A controlled trial of exercise by residents of old people's homes. Age Ageing 1993; 22: 11-15.

30 Reuben DB, Siu AL. An objective measure of physical function of elderly outpatients. The physical performance test. J Am Geriatr Soc 1990; 38: 1105-12.

31 Podsiadlo D, Richardson S. The timed 'Up-andGo': a test of basic functional mobility for frail elderly persons. J Am Geriatr Soc, 1991; 39: $142-48$.

32 Berg KO, Wood-Dauphinee SL, Willian JI, Maki B. Measuring balance in the elderly: validation of an instrument. Can J Public Health 1992; 83 (suppl 2): $\$ 7-11$.

33 Centre for the Study of Ageing and Human Development. Duke OARS multidimensional functional assessment: the OARSA methodology, second edition. Durham (NC): Duke University Medical Centre, 1978.

34 Gerety MB, Mulrow CD, Tuley MR et al. Development and validation of a physical performance instrument for the functionally impaired elderly: physical disability Index. $J$ Gerontol 1993; 48: M33-M38.

35 Simpson JM, New E. In: Redfern S, Ross F ed. Nursing older people. Edinburgh: Churchill Livingstone, 2001: Chapter 20. 